\title{
IT Educators and IT Adoption
}

\section{Sharlett Gillard \\ University of Southern Indiana, Evansville, Indiana, USA}

\author{
sgillard@usi.edu
}

\begin{abstract}
Technology is a constant stream of innovations. Thousands of products are introduced each year. Potential adopters, including IT educators, must determine the right time, if ever, to embrace these new developments and to integrate them into their curricula and/or personal professional endeavors. It is the contention of the author that with regard to the adoption of innovations that purport to improve preparation for and classroom delivery of curriculum, IT educators who teach primarily theory classes must not be a laggard or part of the late majority, need not be an innovator, but should be an early adopter (preferably) or in the lead of the early majority. Further, adoption of IT innovations to improve professional goals and development should follow the same standard.
\end{abstract}

Keywords: IT educator, IT innovations, early adopter, adopter curve

\section{Introduction}

Technology is a constant stream--perhaps flood is more descriptive--of innovations in new technology and changes to existing technologies. Thousands of products are introduced each year. Potential adopters--business, industry, educational institutions, and individuals--must determine the right time, if ever, to embrace these new developments and to integrate them into their existing business process or curricula. Adoption of new products and services into the area of information technology (IT) education is little different from the adoption of new products and services into business organizations or society in general. In IT education, as in the population in general, a few consumers adopt new products early, others wait until they see their friends, competitors, or colleagues with the product and then decide to adopt, while some choose not to adopt.

For this discussion of IT adoption strategies, IT educators are divided into two groups: those who teach primarily theory classes and those who teach hands-on application classes. There are, of course, many hybrid courses that fall into the chasm between theory and application. Further, this discussion highlights IT educators at the theory side of the spectrum, and the arguments presented deal primarily with adoption of IT innovations to assist in course preparation and delivery, but the arguments spill into IT adoption for personal, professional productivity as well. It is the contention of the author that with regard to the adoption of innovations that purport to improve preparation for and classroom delivery of curriculum, IT educators who teach primarily theory classes must not

Material published as part of this journal, either on-line or in print, is copyrighted by Informing Science. Permission to make digital or paper copy of part or all of these works for personal or classroom use is granted without fee provided that the copies are not made or distributed for profit or commercial advantage AND that copies 1) bear this notice in full and 2) give the full citation on the first page. It is permissible to abstract these works so long as credit is given. To copy in all other cases or to republish or to post on a server or to redistribute to lists requires specific permission from the publisher at Publisher@InformingScience.org be a laggard or part of the late majority, need not be an innovator, but should be an early adopter (preferably) or in the lead of the early majority. Further, adoption of IT innovations to improve professional goals and development should follow the same standard. 
Recent studies suggest that there are three levels of new technology adoption for higher education: (a) personal productivity aids, (b) enrichment add-ins, and (c) paradigm shift (Rogers, 2000). Personal productivity aids, such as spreadsheets, allow faculty members to perform tasks faster and more effectively. Most faculty members and higher education institutions use personal productivity aids. Enrichment add-ins such as e-mail or Web pages enhances classroom presentations and homework assignments. This level of technology adoption is very common for many colleges and universities. The highest level of technology adoption is labeled paradigm shift. At this level, faculty members redesign teaching and learning activities to take full advantage of new technology. Massy and Wilger (1998) argued that most faculty members and institutions of higher education operate almost entirely at levels a and b (Hall, 2003).

Additionally, the adoption of an innovation can occur at both the organizational and individual levels. In many cases, it is impossible for an individual to adopt specific technology until the organization has adopted it (Rogers, 1995). "There are several compelling reasons why institutions [of higher education] will have to make continuing and significant investments in information technology. They generally fall into three categories: competitive position; teaching, learning, and curriculum enhancement; and student preparation for the labor market" (Green, 1995). An individual's decision to adopt a specific technology "is the perceived value the individual ascribes to the innovation, and whether the individual engages in communication with other adopters" (Marcus, reported in Gilbert, 1995). Academia, not unlike other entities, has its own unique set of values, influences, politics, resources, etc. that drive decisions regarding adoption of innovations. When a particular innovation is available to academics, however, it frequently becomes an individual choice to embrace or disregard the innovation.

\section{Innovation Characterized}

That new products come and go is a well-known fact documented by the U.S. Census Bureau. That a high percentage of those introductions fail is also documented. Given the explosion of technology, it is probably safe to posit that a large portion of those product introductions and failures were in the IT field! Nonetheless, the demand for technology-enhanced learning environments no doubt will grow substantially over the next decade as society, the academic community, and students continue to expect the educational process to employ technology comparable to that found in the "real world" (Hall, 2003). So when is it appropriate to adopt an IT innovation for educational purposes? What influences drive the adoption decision for educators?

Borrowing from marketing theory, "innovation refers to new things and ideas and new ways of behaving and interacting with things" (Arnould, Price, \& Zinkhan, 2004). Continuous innovations require little behavioral changes. For general classroom and personal use by IT educators, that may include LCD projection equipment, laser pointers, and minor software upgrades. The spectrum of continuous innovations includes fads, fashions and trends. Since fads are characterized as shortlived fashions, for IT educators the super disk might equate to a fadBit made a splash, but the ripples quickly disappeared in the vast sea of technology. Will today's key-chain storage devices (flash or jump drives) be just a fad? An illustration of IT fashion, on the other hand, might be WordStar--it was fashionable to be using a word processing application at a time when few were available, but the "fashionable" application soon gave way to other innovations. Today's Zip disks may well be a fashion as RW CD's flood the market. Trends have a longer duration and may even define an era. Floppy disks are good examples of a trend that is currently fading as a floppy drive becomes a "special request" add-on to new computers. Could Microsoft be a current trend too? Is this Bill=s era? What new innovation will define the next IT era? 
Dynamically continuous and discontinuous innovations round out the marketing continuum of innovation categories. Dynamically continuous innovations require either major behavioral changes in a relatively unimportant area or a minor behavioral change in an area of importance to the individual (Arnould et al., 2004). New textbook adoption might fall in this category when the textbook is an integral part of a class. The textbook is very important to the instructor, but its adoption may require only a minor change in behavior. The use of email might also be considered to fall into this category. Discontinuous innovations require major behavioral changes in an area of importance to the individual (Arnould et al., 2004). A number of IT educators might consider new software/hardware adoptions and software changes to fall in this category: adoption of Blackboard, on-line course offerings, switching from VB6 to VB.Net. Teaching is certainly of major importance to an educator, and a change in the method of delivery or the course content requires major behavioral changes.

\section{Adopter Categories and Characteristics}

Researchers at Iowa State University in 1957 developed the technology-adoption life cycle model to track farmers' use of hybrid-seed corn. Others have since repeatedly applied and modified it to describe adoption behavior for other application populations (Cravotta, 2003). Each of the models depicts five adopter categories: innovators, early adopters, early majority, late majority, and laggards. The characteristics associated with each adopter category are relatively consistent among the derivative models (Geoghegan, 1994; Moore, 1991; Rogers, 1983). Adopters jump into the market at varying points along the innovation's life cycle. The typical marketing adoption curve, shown in Figure 1, shows the phase of the innovation's life cycle at which each adopter

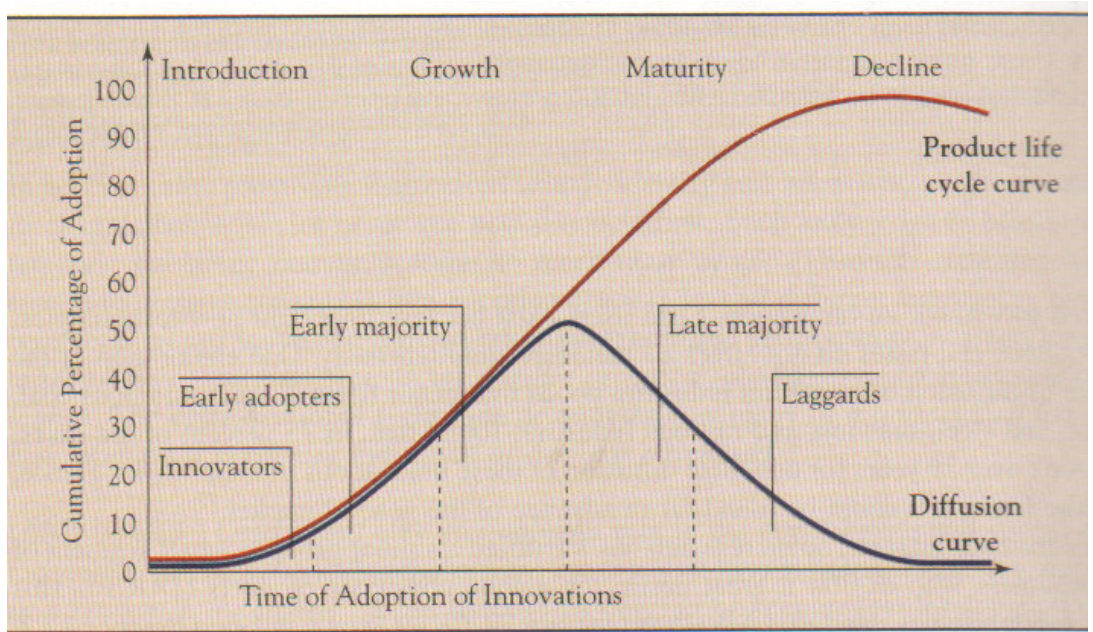

Figure 1: Relationship of the diffusion process to the product life cycle category enters the process and the percent of adopters falling into each category.

The first group, Innovators, representing about 3\% of the subject population, begins using an innovation during the first half of the introduction phase of the product life cycle. They are characterized as being venturesome, less risk averse, and well educated. They also tend to actively seek information in areas of interest via both media and their interpersonal networks of people. (Berkowitz, Hartley, \& Rudelius, 2000). Faculty innovators tend to be the campus "techies" who are intrigued by new hardware or software and are able to learn the new technology on their own (Geoghegan, 1994).

Early Adopters begin using an innovation during the introduction phase of the product life cycle and represent about $10 \%$ of the population. The group tends to be leaders in their social arena and to influence the opinions of associates (Berkowitz et al., 2000). Geoghegan (1994) characterizes 
faculty Early adopters as visionaries who combine their competence and desire into integrating new technologies into the classroom and the teaching process.

The Early Majority occupies the center position in the adopter categories. According to marketing theory, this group is noted for making deliberate, calculated decisions and rely more on interpersonal contacts as sources of information rather than on media sources. They enter the process during the growth phase of the product life cycle (Berkowitz et al., 2000). Relating more specifically to faculty, the Early Majority, typically the next 35\% to adopt instructional technology are receptive to the technology but only after it has been shown to enhance teaching and student learning (Geoghegan, 1994).

The next $35 \%$ of adopters, the Late Majority, enter the process during the maturity phase of the product life cycle. They are skeptical and doubtful of the benefits of adopting an innovation. But, by the time an innovation reaches maturity, the cost is often lower; and that, coupled with a sense of social pressure ("everyone else has one" or "everyone else is doing it"), may be sufficient to entice adoption (Berkowitz et al., 2000). Likewise, Geoghegan (1994) notes that the Late Majority faculty members are skeptical and must be convinced or even coerced to use new technology in the classroom.

The final category in the adoption curve is the Laggards, accounting for about $17 \%$ of the population. By the time the Laggards enter the market, the product life cycle has started to decline. This group is typically less educated than the others, they have a fear of debt, and they rely heavily on a small network of close personal contacts for information (Arnould et al., 2004). The Laggards among the faculty members have absolutely no interest in using new technology in the classroom and may express opposition to its implementation.

Education literature sometimes refers simply to early adopters and mainstream faculty or to early adopters and those who aren't (Gilbert, 1995; Backhouse, 2003; Johnson, 1999). Gilbert (1995) reports Geoghegan's view that early adopters are characterized as visionaries who see technology as something they can use to enable "breakthrough improvements in teaching and learning" whereas the mainstream faculty "tends to focus more on the problems, processes, and tasks at hand than on the tools that might be used to address them." Some of the differences between early adopters and mainstream faculty are shown in Table 1. As noted, Early Adopters are characterized as self-sufficient, risk-taking visionaries with a strong technology focus, whereas the mainstream faculty need support, are risk-averse, conservative, and have a strong process focus.

\begin{tabular}{|l|l|}
\hline \multicolumn{2}{|c|}{ Table 1. Differences between early adopters and mainstream faculty } \\
\hline \multicolumn{1}{|c|}{ Early Adopters } & \multicolumn{1}{c|}{ Mainstream Faculty } \\
\hline Favor revolutionary change & Favor evolutionary change \\
\hline Visionary & Pragmatic or conservative \\
\hline Strong technology focus & Strong problem and process focus \\
\hline Risk-takers & Risk-averse \\
\hline Experimenters & Want proven applications of compelling value \\
\hline Largely self-sufficient & May need significant support \\
\hline "Horizontally" networked & "Vertically" networked \\
\hline
\end{tabular}

In Table 1, "horizontal" networks refers to personal networks that have a high proportion of interdisciplinary and cross-functional links, whereas "vertical" networks refers to those whose linkages are more concentrated within a single discipline or discipline area. 


\section{Factors Influencing Adoption by IT Educators}

College and university educators in general and IT educators in particular have a unique set of values, motivators, organizational politics and alliances that influence technology adoption decisions. It is usually not as simple as "I want to adopt," or "I don=t want to adopt." First, adoption decisions are often committee decisions. The committee could consist of educators, administrators, technical support staff, advisory committees, students, etc. Whatever the make-up, organizational politics will play a part. Who=s budget will be impacted? Who=s time will be required? When? Where? How long? Doing what?

Resources are also a variable when considering innovation adoption. Resources include "access to hardware or software, the money to purchase, training, time to learn, and adequate support." (Gilbert, 1995) Faculty are all too familiar with being expected to learn new subject matter, prepare new teaching materials, construct new evaluation instruments, and deliver appropriate classroom instruction without adequate lead time or training. How often do IT educators install software, network a lab or troubleshoot software or hardware problems because support resources were not available in a timely manner?

Perceived value is another factor in adoption decisions. What benefits might the innovation create? What are the negative aspects? Faculty will not embrace technology unless the overall benefits exceed the costs associated with learning and accessing it (Gilbert, 1995). Initial reaction to "value" might focus on the classroom. However, benefits are derived from other areas as well. Would the innovation bolster research capabilities? Massy and Zemsky (1995 reported in Hall, 2003), in identifying barriers to the adoption of new technology in the teaching and learning environments, noted that there are few incentives for innovative teaching but significant incentives for research. Is there a reward system in place that would make adoption worthwhile? Hagner (2000) found that faculty rewards do not impede "early adopters" and "second-wave" faculty from participating in innovative instruction, whereas the "third-wave" of faculty members adopt only when adoption is seen "as a way to advance their professional careers." Would adoption ally one with key stakeholders in some political arena? Would adoption improve the perceived quality of education afforded students? Would graduates be more employable? Would more students be attracted as majors in the program? Value comes in many shapes and sizes.

Communication with other adopters is an equally significant factor and has an important link to social learning theory. "Social learning theory suggests that we learn in a social context, observing the behaviors of others and modeling on what we see" (Marcus, reported in Gilbert, 1995). A network of professional contacts with colleagues on our own campus as well as those in IT disciplines throughout the world (as our global community becomes ever more closely linked), and professionals working in business and industry fosters an exchange of opinions, ideas, and experiences that influence adoption and continued use of innovations.

Even necessity is sometimes a driving factor in adoption. For example, consider a faculty member who is using, say, Windows 98. A department or school decision to embrace Windows XP would force adoption on the individual faculty member. Likewise, an educator using a computer with inappropriate hardware to run newly acquired software would be forced to upgrade or abandon the software and remain status quo.

\section{Conclusion}

Institutions of higher learning generally have a well defined leadership role for their community and their identified service area. As a leader it is important to be among those at the "front of the pack" in the products and services adoption curve. One cannot exercise this leadership role as a 
"laggard" or a member of the "late majority." Change in the IT field is moving forward at a phe nomenal rate. It often requires a significant investment of financial, time, and energy resources to adopt new technologies. Most of us resist change and find a comfort zone in status quo. However, IT educators should not succumb to complacency but should accept their position of leadership and embrace change.

The segment of IT educators who are immersed in theory may not view their role as an agent of change in regard to technology adoption, which is one of the characteristics of an innovator, and perhaps rightly so. Their classroom delivery may not depend on the use of technology, or technology may simply enhance delivery but not occupy the focal point of the delivery. In theory classes, which tend to be lecture classes, technology is used incidentally to illustrate a particular concept. Thus, perhaps it isn't paramount that they use or even know about the newest, and perhaps as of yet unproven, technology. To remain on a technology par with many of the students in college classrooms, however, the IT educator should be IT literate and current. The IT educator should be aware of developments in the field and should update their lectures to include relevant current innovations. IT educators should be able to engage in informed discussions with colleagues and students regarding new technology and should be able to defend non-adoption of technology when that is the case.

It is important, too, to teach by example. The increasing importance of IT to businesses is more than evident, in product and service designs, customer relationship management, supply chain processes, knowledge management, and business analyses. IT enables global expansion and virtual organization forms. Computer-mediated communications are a common business practice, and business strategies are increasingly computer-enabled. Given the importance of IT to business, does it follow that IT should be important for business education? Clearly, part of learning to conduct business is learning to conduct business with technology (Brennan, Miller, \& Moniotte, 2001). IT educators who teach primarily theory classes must not be a laggard or part of the late majority, need not be an innovator, but should be an early adopter (preferably) or in the lead of the early majority. Some risk should be acceptable. If we expect our students to be ready for an ITpermeated business environment, we must "walk the walk and talk the talk" before them.

\section{References}

Arnould, E., Price, L. \& Zinkhan, G. (2004). Consumers ( $2^{\text {nd }}$ ed.). Boston, MA: McGraw Hill Irwin.

Backhouse, B. (2003). Information and communication technology integration: Beyond the early adopters. TechTrends, 47 (3), 5-8.

Berkowitz, K., Hartley, \& Rudelius. (2000). Marketing (6 ${ }^{\text {th }}$ ed.). Boston, MA: McGraw Hill Irwin.

Brennan, L. L., Miller, J. R., \& Moniotte, S. M. (2001). Herding cats to water: Benchmarking the use of computers in business education. Journal of Education for Business, 76 (6), 345-352.

Gilbert, S. (1995). An 'online' experience: Discussion group debates why faculty use or resist technology. Change, 27 (2), 28-45.

Cravotta, R. (2003). Welcome to the jungle. EDN, 48 (24), 38-47.

Geoghegan, W. H. (1994). What ever happened to instructional technology? Paper presented at the $22^{\text {nd }}$ Annual Conference of the International Business Schools Computing Association. Baltimore, MD.

Green, K. C. \& Gilbert, S. W. (1995). Great expectations. Change, 27 (2), 8-18.

Hagner, P. R. (2000). Engagement and support in the new learning environment. Educause Review. Retrieved February 24, 2004 from http://www.educause.edu/pub/er/erm00/erm005.html 
Hall, M. \& Elliott, K.M. (2003). Diffusion of technology into the teaching process: Strategies to encourage faculty members to embrace the laptop environment. Journal of Education for Business, 78 (6), 301307.

Johnson, M. J., Schwab, R. L. \& Foa L. (1999). Technology as a change agent for the teaching process. Theory into Practice, 38 (1), 24-30.

Massy, W. F. \& Wilger, A. K. (1998). Technology's contribution to higher education productivity. New Directions for Higher Education, 103, 49-59.

Massy, W. F. \& Zemsky, R. (1995). Using information technology to enhance academic productivity. Presented at the 1995 CAUSE Conference.

Moore, G. A. (1991). Crossing the chasm: Marketing and selling high-technology products to mainstream customers. New York: Harper Business.

Rogers, D. L. (2000). A paradigm shift: Technology integration for higher education in the new millennium. Educational Technology Review, Spring/Summer, 19-27.

Rogers, E. M. (1983). Diffusion of innovations ( $3^{\text {rd }}$ ed.). New York: Free Press.

Rogers, E. M. (1995). Diffusion of innovations (4 ${ }^{\text {th }}$ ed.). New York: Free Press.

\section{Biography}

An associate professor of computer information systems at the University of Southern Indiana, Dr. Gillard's research interests include project management and curricular issues in CIS. Dr. Gillard's teaching career has been primarily in midwestern universities. Her non-teaching experience has included positions such as administrative assistant for a TV news broadcast program in Los Angeles, office manager for a consortium of developers, builders, commercial real estate agents and bookkeepers, administrator of a satellite college campus, and academic dean of a business college. 